\title{
Erratum to: The patient-reported outcome content of international ovarian cancer randomised controlled trial protocols
}

\author{
Rebecca Mercieca-Bebber ${ }^{1,2}$ (D) Michael Friedlander ${ }^{3,4}$ - Peey-Sei Kok ${ }^{3,4}$. \\ Melanie Calvert ${ }^{5} \cdot$ Derek Kyte $^{5} \cdot$ Martin Stockler $^{3} \cdot$ Madeleine T. King $^{1,2,4}$
}

Published online: 22 April 2017

(C) Springer International Publishing Switzerland 2017

\section{Erratum to: Qual Life Res (2016) 25:2457-2465 DOI 10.1007/s11136-016-1339-x}

In this article by $\mathrm{R}$ Mercieca-Bebber an error was made in the flow diagram (Fig. 1) regarding the number of ovarian cancer randomised controlled trials which met the eligibility criteria. It was incorrectly stated that there were 41 eligible trials, however in fact there were 36 eligible trials.
In the limitations it was stated that $37 \%$ of 41 eligible trial protocols were not obtained, however this should be revised to "28\% of 36 trial protocols". Because the trials concerned were not included in our analysis of trial protocols, this correction does not alter the results or interpretation of the study results in any way, therefore the validity of the analysis is unaffected by this error. The revised flow diagram is presented below.

The online version of the original article can be found under doi:10.1007/s11136-016-1339-x.

Rebecca Mercieca-Bebber

Rebecca.mercieca@sydney.edu.au

1 Central Clinical School, Sydney Medical School, University of Sydney, Sydney, NSW 2006, Australia

2 Quality of Life Office, Psycho-oncology Co-operative Research Group, School of Psychology, University of Sydney, Level 6 North, Chris O’Brien Lifehouse C39Z, Sydney, NSW 2006, Australia

3 NHMRC Clinical Trials Centre, University of Sydney, Sydney, NSW 2006, Australia

4 Australian New Zealand Gynecological Oncology Group (ANZGOG), Camperdown, NSW 2050, Australia

5 Institute of Applied Health Research, University of Birmingham, Birmingham, UK 

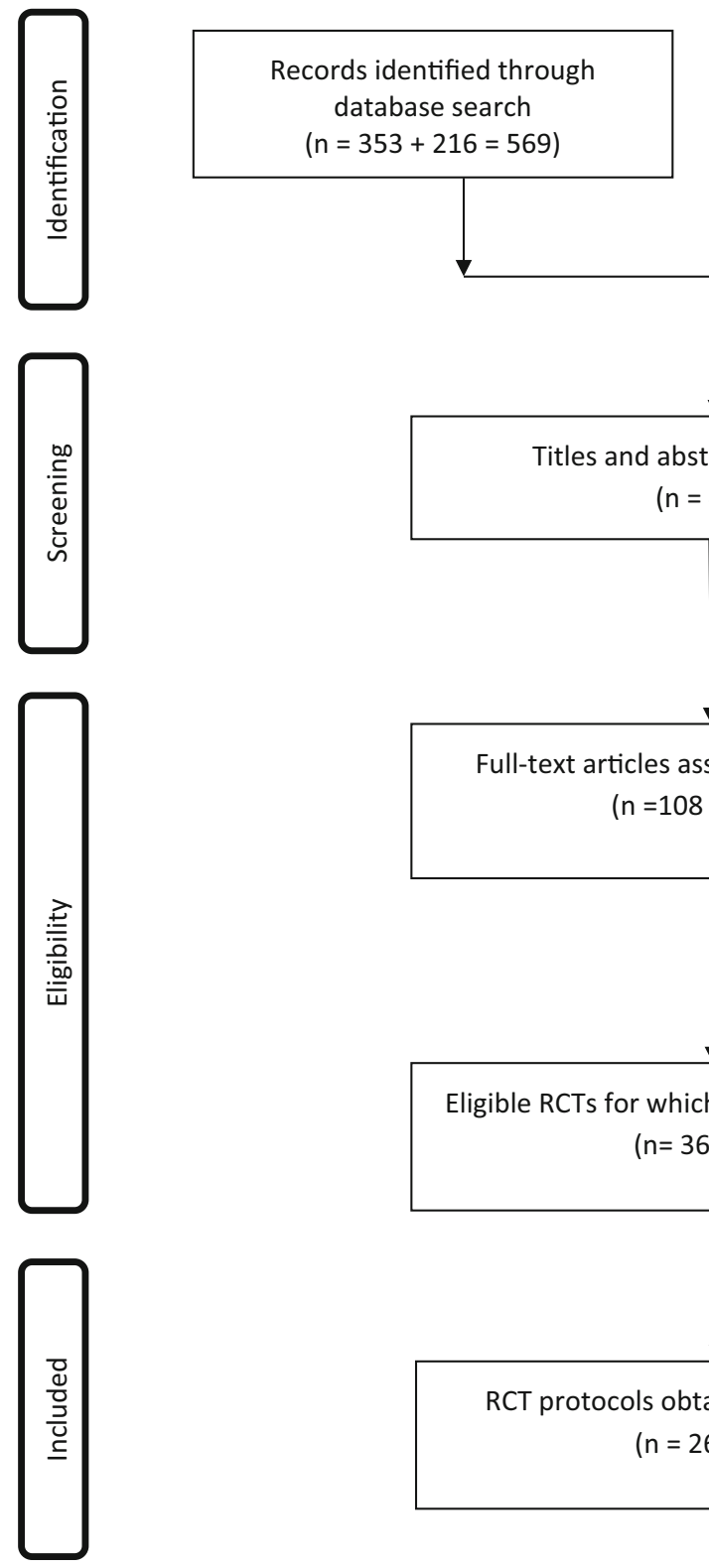

Additional records identified by field experts \& reference list search

$(n=353+216=569)$

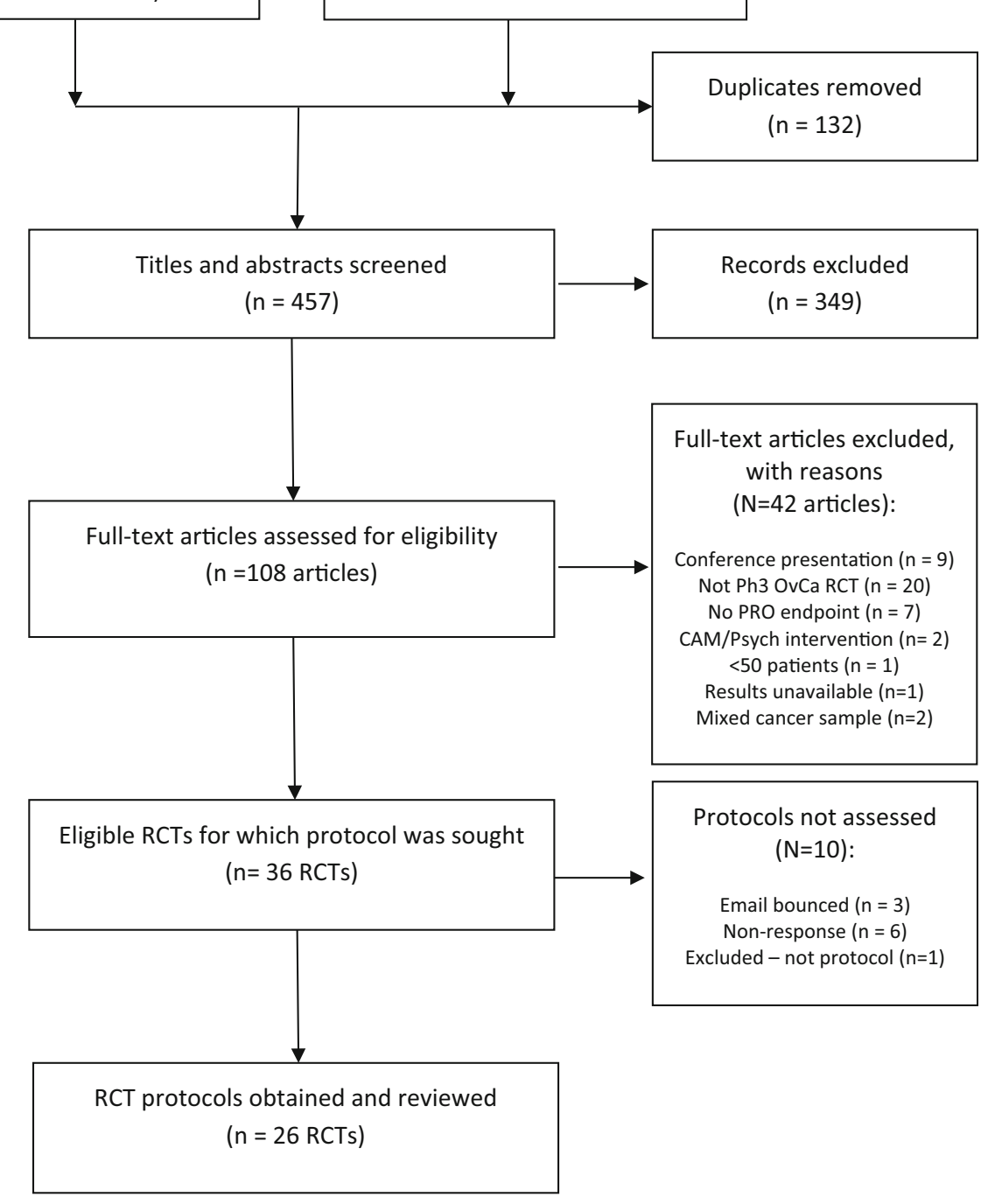

Fig. 1 Flow diagram of included RCTs 